\title{
Исследование способов концентрирования продуктов ПЦР для последующего секвенирования с помощью методов, основанных на сорбции нуклеиновых кислот
}

\author{
(C) 2020 Нестерова Е.Ю. ${ }^{1}$, Дворецкая Ю.Д. ${ }^{1}$, Грязнова М.В. ${ }^{1}$, \\ Гладких М.И. ${ }^{1}$, Сыромятников М.Ю. ${ }^{1}$, Старкова Н.Н. ${ }^{2}$, Попов В.Н. ${ }^{1}$ \\ ${ }^{1}$ Воронежский государственный университет инженерных технологий, Воронеж \\ ${ }^{2}$ Maritime College, State University of New York, New York, USA
}

Поступила в редакцию 19.11.2020 г

DOI: $10.17308 /$ sorpchrom.2020.20/3146

В последнее время широкое распространение получили методы, основанные на секвенировании ДНК. Зачастую методы секвенирования требуют выделения нуклеиновых кислот из исследуемого материала, проведение ПЦР для амплификации маркерных участков ДНК и их последующее преобразование в библиотеки ДНК для секвенирования. Иногда концентрация полученных продуктов ПЦР недостаточна для проведения секвенирования. Целью данной работы явился подбор оптимального метода концентрирования продуктов ПЦР (ампликонов) с помощью методов, основанных на сорбции нуклеиновых кислот. Установлено, что наиболее оптимальным для концентрирования ампликона методом является применение колонок с силикой и использование магнитных частиц. Концентрация ампликона, полученного при амплификации бактериальной ДНК, возрастала в 3.14 раза при использовании набора, основанного на применении колонки с силикой (диоксидом кремния), и в 2.74 раза при использовании магнитных частиц. Концентрация ампликона, полученного при амплификации грибковой ДНК, возрастала в 4.72 раза при использовании набора, основанного на применении колонок с силикой, и в 3.70 раза при использовании магнитных частиц. Различная эффективность методов концентрирования по отношению к продуктам ПЦР, полученным в ходе амплификации бактериальной и грибковой ДНК, может быть обусловлена различной длиной фрагмента - чем короче фрагмент, тем выше эффективность концентрирования. Магнитные частицы позволяли получать более гомогенный препарат ампликона, чем в случае применения колонки с силикой, что может быть важным для последующего приготовления библиотек секвенирования и непосредственно проведения секвенирования ампликона. Представленные способы концентрирования ампликонов после реакций ПЦР на основе сорбирующих свойств силики и магнитных частиц повысят чувствительность методов секвенирования и позволят проводить анализ даже в тех случаях, когда изначальное количество ДНК не позволяет наработать нужное для проведения секвенирования количество ампликона.

Ключевые слова: ДНК, ампликон, секвенирование, силика, магнитные частицы, концентрирование.

\section{Введение}

За последние годы высокопроизводительное секвенирование ДНК стало тесно интегрироваться с генетическими исследованиями [1]. Поскольку современные технологии позволяют секвенировать миллионы или миллиарды фрагментов ДНК параллельно при относительно низких затратах, объем генерации данных часто ограничивается трудностями при подготовке образцов, а не возможностями секвенирования $[2,3]$. Чистота и количество экстрагированной ДНК влияют на ключевые тех- 
нические этапы пробоподготовки библиотек секвенирования [4]. Современные методы секвенирования требуют выделения нуклеиновых кислот из исследуемого материала и их последующего преобразования в библиотеки ДНК. Это достигается путем прикрепления синтетических адаптеров к их концам, что обеспечивает формат, позволяющий их амплификацию и праймирование реакции секвенирования. Потери молекул происходят на обоих этапах подготовки образца и затрудняют работу с небольшими количествами нуклеиновых кислот [5]. Кроме того, молекулы ДНК иногда присутствуют в форме, которая затрудняет их успешное извлечение и подготовку библиотек ДНК. Полимеразная цепная реакция (ПЦР) хоть и является высокоспецифичным и чувствительным методом накопления ампликонов, не всегда ее разрешающей способности достаточно для наработки необходимого количества материала $[6,7]$. В стремлении максимизировать концентрацию продукта зачастую необходимо проведение дополнительного промежуточного этапа.

Твердофазная экстракция ДНК лежит в основе большинства общедоступных наборов для выделения и очистки нуклеиновых кислот, которые также могут быть использованы для концентрирования исследуемого образца [8]. Общий принцип данных методов заключается в уникальных свойствах носителей на основе силики (диоксида кремния) для селективного связывания ДНК. За счет высокой афинности отрицательно заряженного остова ДНК к положительно заряженным силикатным частицам происходит связывание ДНК с неорганическим носителем, с последующими этапами отмывки от примесей и элюцией очищенного продукта [9-12].

Принцип метода магнитной сепарации основан на обратимом связывании ДНК на поверхности магнитных частиц, которые легко осаждаются из суспензии с помощью магнитного штатива [13]. Метод не требует фильтрации ДНК через сорбент методом центрифугирования, что снижает вероятность дополнительной фрагментации ДНК.

Поверхность магнитных частиц покрыта полимерной пленкой, на которой экспонированы ковалентно связанные карбоксильные группы. Метод выделения ДНК с использованием магнитных частиц основан на двух принципах: способность поверхности частиц обратимо связывать молекулы ДНК; возможность легко осадить ресуспендированные магнитные частицы из водного раствора при помощи магнитного поля $[14,15]$.

В отсутствии магнитного поля частицы между собой не слипаются, но на магните происходит их моментальная иммобилизация, что позволяет быстро сменить раствор, в котором они ресуспендированы.

Целью данной работы явился подбор оптимального метода концентрирования фрагментов ПЦР, которые были получены при амплификации нуклеиновых кислот бактерий и грибов.

\section{Эксперимент}

В качестве объектов исследования использовали смесь ДНК бактерий Bacillus subtilis и Pseudomonas sp., а также ДНК грибов Trichoderma sp.

Полимеразная цепная реакция проводилась с использованием Таqполимеразы на приборе Mastercycler personal (Eppendorf, Германия). Смешивали в пробирке $0.25 \mathrm{~cm}^{3}$ следующие компоненты: $5 \mathrm{X}$ реакционная смесь qPCRmix-HS (Евроген, Россия) - 5 мкл; 5 мкМ прямой праймер - 1 мкл; 5 мкМ обратный праймер 1 мкл; ДНК - 2 мкл; деионизованная вода - до 25 мкл. Использовали следующий температурный цикл: $94^{\circ} \mathrm{C} 4$ мин, 35 циклов: $94^{\circ} \mathrm{C} 30$ сек $54^{\circ} \mathrm{C} 30$ сек, $72^{\circ} \mathrm{C} 45$ сек, конечная элонгация $72^{\circ} \mathrm{C} 10$ мин. В качестве праймеров использовали следующие:

Нестерова и др. / Сорбционные и хроматографические процессы. 2020. Т. 20. № 6. С. 782-788 
для амплификации ДНК грибов - прямой ITS1 TCCGTAGGTGAACCTGCGG, обратный ITS4 TCCTCCGCTTATTGATATGC [16]; для амплификации ДНК бактерий 337F GACTCCTACGGGAGGCWGCAG, обратный 1100R GGGTTGCGCTCGTTG [17]. Визуализацию продуктов ПЦР проводили с помощью электрофореза в $2 \%$ агарозном геле.

Концентрацию ДНК измеряли с помощью флуориметра Qubit 4 (Thermo Fisher Scientific, США). Исследовались 3 способа концентрирования ампликона:

1. Концентрирование ампликонов на колонке с силикой проводили с помощью коммерческого набора для очистки ДНК из агарозного геля и реакционных смесей Cleanup Standard (Евроген, Россия) согласно приложенной инструкции (https://evrogen.ru/kit-user-manuals/BC022.pdf).

2. Концентрирование ампликонов с использованием магнитных частиц проводили с помощью суспензии магнитных частиц для очистки ДНК из реакционных смесей CleanMag DNA (Евроген, Россия) согласно приложенной инструкции (https://evrogen.ru/kit-user-manuals/BC35_CleanMagDNA.pdf).

3. Концентрирование ампликонов с использованием силики без колонки проводили с помощью набора Проба-ГС (ДНК-технология, Россия) согласно приложенной инструкции (https://www.dna-technology.ru/sites/default/files/180-4 probags_ivd_k_2019-06-25_1.pdf), с модификацией, которая обусловлена тем, что на первом этапе вместо образца биологического материала добавляли 125 мкл реакционной смеси после проведения ПЦР (см. выше).

\section{Обсуждение результатов}

На первом этапе мы смоделировали эксперимент, при котором была получена низкая концентрация ампликонов, достигалось это путем пятикратного разбавления ампликона с помощью деионизированной воды после реакции ПЦР. В результаты были получены следующие концентрации продуктов ПЦР: для бактерий 11.6 мкг/мкл; для грибов - 8.17 мкг/мкл. Далее 125 мкл разбавленной смеси (объем разбавленной в 5 раз реакционной смеси) использовали для последующих процедур концентрирования с использованием трёх методов (см. материалы и методы). В результате было выявлено, что концентрация ампликона, полученного при амплификации бактериальной ДНК, возрастала в 3.14 раза при использовании набора, основанного на применении колонки с силикой, и в 2.74 раза при использовании магнитных частиц (рис. 1).

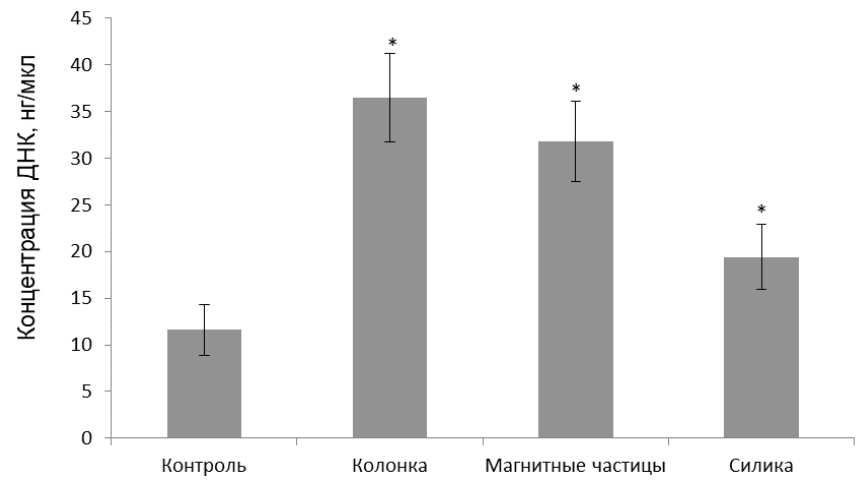

Рис. 1. Концентрация ДНК после амплификации бактериальной ДНК

в зависимости от способа концентрирования ампликона. * $\mathrm{p}<0.05$.

Fig. 1. DNA cconcentration depending on the method of amplicon concentration after bacterial DNA amplification. ${ }^{*} \mathrm{p}<0.05$. 
При проведении электрофореза в агарозном геле было установлено, что ампликон, полученный в ходе концентрирования с помощью магнитных частиц, был более гомогенен по отношению к ампликону, полученному с помощью набора на основе колонок с силикой (рис. 2).

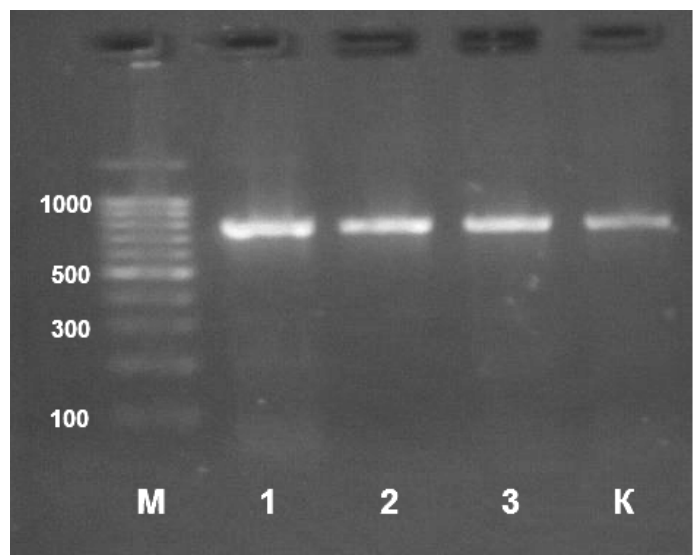

Рис. 2. Электрофореграмма фрагментов нуклеиновых кислот после проведения концентрирования ампликона, полученного в ходе амплификации бактериальной ДНК. М - маркеры известной длины, 1 - набор на основе колонки с силикой, 2 - магнитные частицы, 3 - набор на основе силики без колонки, К - контроль.

Fig. 2. Electrophoregram of nucleic acid fragments after concentration of the amplicon obtained after amplification of bacterial DNA. M - markers of known length, 1 - kit based on column with silica, 2 - magnetic particles, 3 - kit based on silica without column, $\mathrm{K}$ - control.

При оценке способов концентрирования ампликонов, полученных в ходе амплификации грибковой ДНК, было установлено, что эффективность методов концентрирования ампликонов, в целом, была выше, чем при применении этих методов по отношению к ампликону, полученному при амплификации бактериальной ДНК. Концентрация ампликона, полученного при амплификации грибковой ДНК, возрастала в 4.72 раза при использовании набора, основанного на применении колонок с силикой, и в 3.70 раза при использовании магнитных частиц (рис. 3).

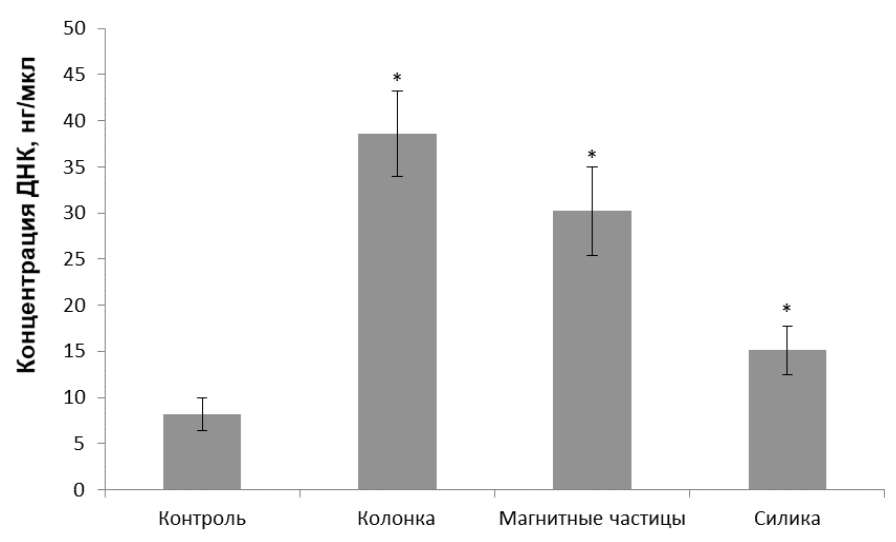

Рис. 3. Концентрация ДНК после амплификации грибковой ДНК в зависимости от способа концентрирования ампликона. * $\mathrm{p}<0.05$.

Fig. 3. DNA cconcentration depending on the method of amplicon concentration after fungal DNA amplification. $* \mathrm{p}<0.05$. 
При проведении электрофореза в агарозном геле было установлено, что ампликон, полученный в ходе концентрирования с помощью магнитных частиц, также был более гомогенен по отношению к ампликону, полученному с помощью наборов, основанных на колонках с силикой(рис. 4).

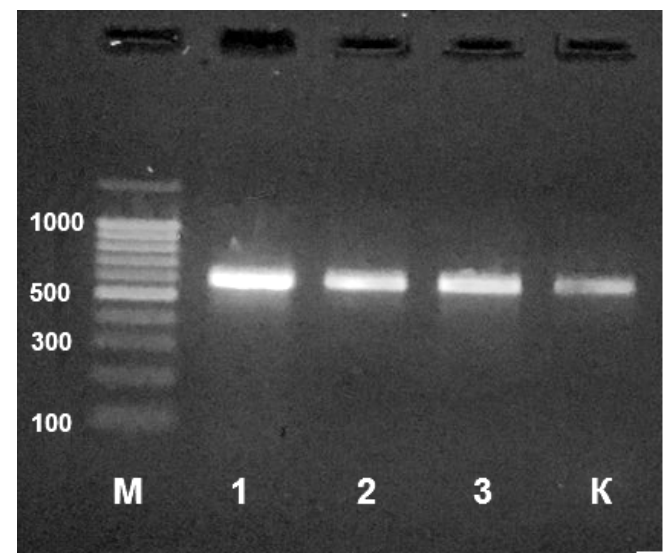

Рис. 4. Электрофореграмма фрагментов нуклеиновых кислот после проведения концентрирования ампликона, полученного в ходе амплификации грибковой ДНК. М - маркеры известной длины, 1 - набор на основе колонки с силикой, 2 - магнитные частицы, 3 - набор на основе силики без колонки, К - контроль.

Fig. 4. Electrophoregram of nucleic acid fragments after concentration of the amplicon obtained after amplification of fungal DNA. M - markers of known length, 1 - kit based on column with silica, 2 - magnetic particles, 3 - kit based on silica without column, $\mathrm{K}-$ control.

Различная эффективность методов концентрирования по отношению к продуктам ПЦР, полученным в ходе амплификации бактериальной и грибковой ДНК, может быть обусловлена различной длиной фрагмента. При амплификации бактериальной ДНК размер продукта ПЦР выше, чем при амплификации грибковой ДНК. Возможно, эффективность методов концентрирования возрастает при уменьшении размера продукта амплификации. Это требует дополнительных исследований.

В ходе проведения экспериментов было установлено, что наиболее оптимальным для концентрирования ампликона является применение колонок с силикой и использование магнитных частиц. Максимальная концентрация ДНК была получена при применении колонки с силикой. Чуть меньшая концентрация ДНК была получена при применении магнитных частиц, однако магнитные частицы позволяли получать более гомогенный препарат ампликона, чем в случае применения колонки с силикой. Это может быть важным для последующего приготовления библиотек секвенирования и непосредственно проведения секвенирования ампликона.

Концентрирование ампликона может быть полезным в тех случаях, когда изначально было низкое содержание ДНК целевого организма и амплифицированного продукта ПЦР недостаточно для приготовления библиотек секвенирования. В этом случае возможно приготовление библиотек для секвенирования по следующему алгоритму: провести одновременно несколько ПЦР-реакций (количество реакций может варьировать, при этом суммарный конечный объем реакционных смесей не должен превышать объем колонок либо предельный объем для магнитных частиц), сконцентрировать продукты ПЦР из реакционных смесей до объема 20-50 мкл, провести секвенирование сконцентрированного продукта ПЦР. 


\section{Заключение}

Таким образом установлено, что наиболее оптимальным методом для концентрирования ампликона является применение колонок с силикой и использование магнитных частиц. Магнитные частицы позволяли получать более гомогенный препарат ампликона, чем в случае применения колонок с силикой. Представленные способы концентрирования ампликонов после реакций ПЦР на основе сорбирующих свойств силики и магнитных частиц повысят чувствительность методов секвенирования и позволят проводить анализ даже в тех случаях, когда изначальное количество ДНК не позволяет наработать нужное для проведения секвенирования количество ампликона.

Работа поддержана министерством науки и высшего образования в рамках нацпроекта «Наука» (проект FZGW-2020-0001, уникальный номер реестра государственных заданий 075001 Х39782002).

\section{Список литературы/References}

1. Tipu H.N., Shabbir A., Journal of the College of Physicians and Surgeons Pakistan, 2015, Vol. 25, No 3, pp. 210-215. Available at: https://studyres.com/doc/22754812/evolutionof-dna-sequencing---journal-of-the-college-ofp. (accessed 11 December 2020).

2. Ke R., Mignardi M., Pacureanu A., Svedlund J. et al., Nature Methods, 2013, Vol. 10, No 9, pp. 857-860. DOI: 10.1038/nmeth.2563.

3. Lee J.H., Daugharthy E.R., Scheiman J., Kalhor R. et al., Science, 2014, Vol. 343, No 6177, pp. 1360-1363. DOI: 10.1126/science. 1250212 .

4. Endrullat C., Glökler J., Franke P., Frohme M., Applied \& Translational Genomics, 2016, Vol. $\quad 10, \quad$ pp. 2-9. DOI: 10.1016/j.atg.2016.06.001.

5. Gansauge M.T., Gerber T., Glocke I., Korlevic P. et al., Nucleic acids research, 2017, Vol. 45, No 10, pp.79. DOI: 10.1093/nar/gkx033.

6. Haque K.A., Pfeiffer R.M., Beerman M.B., Struewing J.P. et al., BMC Biotechnology, 2003, Vol. 3, pp. 20. DOI: 10.1186/1472-6750-3-20.

7. Klaschik S., Lehmann L.E., Raadts A., Hoeft A. et al., Molecular Biotechnology, 2002, Vol. 22, No 3, pp. 231-242. DOI: 10.1385/MB:22:3:231.

8. Katevatis C., Fan A., Klapperich C.M., PLoS One, 2017, Vol. 12, No 5, pp. 1-14. DOI: 10.1371/journal.pone.0176848.
9. Cady N.C., Stelick S., Batt C.A., Biosensors \& Bioelectronics, 2003, Vol. 19, No 1, pp. 59-66. DOI: 10.1016/s0956-5663(03)00123-4.

10.Rimola A., Costa D., Sodupe M., Lambert J.F., et al., Chemical Reviews, 2013, Vol. 113, No 6, pp. 4216-4313. DOI: 10.1021/cr3003054.

11.Zhang Y., Cremer P.S., Current Opinion in Chemical Biology, 2006, Vol. 10, No 6, pp. 658-663. DOI: 10.1016/j.cbpa.2006.09.020.

12.Poeckh T., Lopez S., Fuller A.O., Solomon M.J. et al., Analytical Biochemistry, 2008, Vol. 373, No 2, pp. 253-262. DOI: 10.1016/j.ab.2007.10.026.

13.Berensmeier S., Applied Microbiology and Biotechnology, 2006, Vol. 73, No 3, pp. 495504. DOI: $10.1007 / \mathrm{s} 00253-006-0675-0$.

14. Souza K.C., Salazar-Alvarez G., Ardisson J.D., Macedo W.A., Nanotechnology, 2008, Vol. 19, No 18., pp. 7. DOI: 10.1088/09574484/19/18/185603.

15.Hawkins T.L., O'Connor-Morin T., Roy A., Santillan C., Nucleic Acids Research, 1994, Vol. 22, No 21, pp. 4543-4544. DOI: 10.1093/nar/22.21.4543.

16. White T.J., Bruns T., Lee S., Taylor J., In: PCR Protocols: A Guide to Methods and Applications. New York: Academic Press, 1990, Vol. 18 , pp. 315-322.

17. Techo S., Shiwa Y., Tanaka N., Fujita N. et a1., Int J Syst Evol Microbiol., 2019, Vol. 69, No 8 , pp. 2506-2513. DOI: 10.1099/ijsem.0.003524 


\title{
Analysis of methods for PCR products concentrating for subsequent sequencing using methods based on the sorption of nucleic acids
}

\author{
(C) 2020 Nesterova E.Yu. ${ }^{1}$, Dvoretskaya Yu.D. ${ }^{1}$, Gryaznova M.V. ${ }^{1}$, \\ Gladkih M.I. ${ }^{1}$, Syromyatnikov M.Yu. ${ }^{1}$, Starkova N.N. ${ }^{1}$, Popov V.N. ${ }^{1}$ \\ ${ }^{1}$ Voronezh State University of Engineering Technologies, Voronezh, Russia \\ ${ }^{2}$ Maritime College, State University of New York, New York, USA
}

Methods based on DNA sequencing have become widespread. Often, sequencing methods require the isolation of nucleic acids from the test material, PCR to amplify the marker fragment of DNA, and their subsequent conversion to DNA libraries for sequencing. Sometimes the concentration of the obtained PCR products is insufficient for sequencing. The aim of this study was the selection of the optimal method for PCR products (amplicons) concentrating using nucleic acid sorption-based methods. It was found that the most optimal method for amplicon concentration is the use of columns with silica and the use of magnetic particles. The concentration of amplicon obtained by the amplification of bacterial DNA increased by 3.14 times when using a kit based on a column with silica, and by 2.74 times when using magnetic particles. The concentration of amplicon obtained by amplification of fungal DNA increased by 4.72 times when using a kit based on the columns with silica, and by 3.70 times when using magnetic particles. The different efficiency of concentration methods in relation to PCR products obtained during amplification of bacterial and fungal DNA may be due to different fragment lengths. The maximum concentration of DNA was obtained when using a column with silica. Magnetic particles allowed obtaining a more homogeneous amplicon than in the case of using a column with silica. It can be important for the subsequent preparation of sequencing libraries and direct amplicon sequencing. The presented methods for amplicon concentrating after PCR reactions based on the sorbing properties of silica and magnetic particles will increase the sensitivity of sequencing methods and allow analysis even in cases where the initial amount of DNA does not allow obtaining the necessary amount of amplicon for sequencing.

Keywords: DNA, amplicon, sequencing, silica, magnetic particles, concentration.

Дворецкая Юлия Дмитриевна - младший научный сотрудник лаборатории метагеномики и пищевых биотехнологий, Воронежский государственный университет инженерных технологий, Воронеж

Грязнова Мария Владимировна - младший научный сотрудник лаборатории метагеномики и пищевых биотехнологий, Воронежский государственный университет инженерных технологий, Воронеж

Нестерова Екатерина Юрьевна - младший научный сотрудник лаборатории метагеномики и пищевых биотехнологий, Воронежский государственный университет инженерных технологий, Воронеж

Гладких Мария Ивановна - младший научный сотрудник лаборатории метагеномики и пищевых биотехнологий, Воронежский государственный университет инженерных технологий, Воронеж

Сыромятников Михаил Юрьевич - ведущий научный сотрудник лаборатории метагеномики и пищевых биотехнологий, Воронежский государственный университет инженерных технологий, Воронеж

Попов Василий Николаевич - ректор Воронежского государственного университета инженерных технологий, Воронеж

Старкова Наталья Николаевна - адьюнкт профeccop, Maritime College, State University of New York, Нью-Йорк
Dvoretskaya Yulia D. - Junior researcher at the laboratory of metagenomics and food biotechnologies, Voronezh state university of engineering technologies, Voronezh. e-mail: dyd16@mail.ru

Gryaznova Maria V. - Junior researcher at the laboratory of metagenomics and food biotechnologies, Voronezh state university of engineering technologies, Voronezh. e-mail: mariya-vg@mail.ru

Nesterova Ekaterina Yu. - Junior researcher at the laboratory of metagenomics and food biotechnologies, Voronezh state university of engineering technologies, Voronezh. e-mail: katya.nesterova.1997@mail.ru

Gladkih Maria I. - Junior researcher at the laboratory of metagenomics and food biotechnologies, Voronezh state university of engineering technologies, Voronezh. e-mail: mariya221095@yandex.ru

Syromyatnikov Mikhail Yu. - leading researcher at the laboratory of metagenomics and food biotechnologies, Voronezh state university of engineering technologies, Voronezh. e-mail: mihan.vrn@mail.ru

Popov Vasily N. - Rector of Voronezh state university of engineering technologies, Voronezh. e-mail: pvn@bio.vsu.ru

Starkova Natalia N. - Adjunct professor, Maritime College, State University of New York, New York. email: natalia.n.starkova@gmail.com 